\title{
O ENSINO DE FILOSOFIA NO PROCESSO DE RESISTÊNCIA
}

\author{
Alex Fabiano Correia Jardim ${ }^{1}$ \\ Universidade Estadual de Montes Claros (UNIMONTES) \\ https://orcid.org/0000-0001-8231-1096 \\ E-mail: alex.jardim38@hotmail.com \\ Adhemar Santos de Oliveira ${ }^{2}$ \\ Universidade do Estado da Bahia (UNEB) \\ https://orcid.org/0000-0002-6873-3417 \\ E-mail: adhemar.filosofia@gmail.com
}

\section{RESUMO:}

O presente artigo propõe levantar uma série de problemas para tentar pensar as possibilidades do ensino de filosofia como um processo de resistência e luta contra àquilo que Deleuze e Guattari chamaram de "inimigos da filosofia: os pós-kantianos,o filósofo alemão Friedrich Hegel e especialmente, o marketing. A partir da crítica desenvolvida, abordaremos também como o ensino de filosofia poderia criar linhas de fuga àquilo que Silvio Gallo chamou de ‘educação maior'. Pretendemos pensar a filosofia e a educação tendo como fio condutor, a filosofia da diferença de Gilles Deleuze e Félix Guattari. A ideia é tratar a filosofia com criadora de conceito a partir da ideia de‘pedagogia do conceito', o que nos possibilitaria problematizar uma prática de ensino de filosofia estabelecendo enquanto campo de conversação, a filosofia da diferença e seu ensino, ou seja, tal prática formativa pretende agir por brechas, fazendo emergir possibilidades dos estudantes escaparem na medida do possível, das formas e dispositivos de controle.

PAlaVRaS-ChaVes: Ensino de filosofia; Resistência; Linha de fuga; Pedagogia do conceito; Educação maior; diferença.

\section{THE TEACHING OF PHILOSOPHY IN THE PROCESS OF RESISTANCE}

\begin{abstract}
:
This article proposes to raise a series of problems to try to think of the possibilities of teaching philosophy as a process of resistance and struggle against what Deleuze and Guattari called 'enemies of philosophy: the postKantians, the German philosopher Friedrich Hegel and especially, marketing. Based on the criticism developed, we will also address how the teaching of philosophy could create escape lines from what Silvio Gallo called 'higher education'. We intend to think about philosophy and education based on the philosophy of difference by Gilles Deleuze and Félix Guattari. The idea is to treat philosophy as a concept creator based on the idea of 'concept pedagogy', which would enable us to problematize a philosophy teaching practice, establishing as a field of conversation, the philosophy of difference and its teaching, that is, such formative practice intends to act through loopholes, giving rise to the possibilities of students to escape, as far as possible, from control forms and devices.
\end{abstract}

KEYWORDS: Philosophy teaching; Resistance; Escape line; Concept pedagogy; Higher education; Difference.

${ }^{1}$ Doutor em Filosofia pela Universidade Federal de São Carlos (UFSCAR), São Carlos - SP, Brasil. Professor de Filosofia da Universidade Estadual de Montes Claros (UNIMONTES), Montes Claros - MG, Brasil.

${ }^{2}$ Mestre em Filosofia pela Universidade Estadual de Montes Claros (UNIMONTES), Montes Claros - MG, Brasil. Professor da Universidade do Estado da Bahia (UNEB), Guanambi - BA, Brasil.

JARDIM, Alex Fabiano Correia; OLIVEIRA, Adhemar Santos de. O ensino de filosofia no processo de resistência. Griot : Revista de Filosofia, Amargosa - BA, v.20, n.2, p.332-346, junho, 2020. 


\begin{abstract}
"A filosofia, tal como até agora a entendi e vivi, é a vida voluntária no gelo e nos cumes - a busca de tudo o que é estranho e questionável no existir, de tudo o que a moral até agora baniu" (NIETZSCHE)
\end{abstract}

No contexto pensado por Nietzsche, conforme epígrafe acima, de que a filosofia é um exercício de solidão, levantamos as seguintes questões: a filosofia pode ser ensinada?, qual é a melhor metodologia para ensinar filosofia?, e, como resistir ao campo atrativo do império das opiniões nos tempos de caos encontrados hoje no Brasil?

Ao pensar o ensino de filosofia na educação básica, partimos dos pressupostos dos dispositivos legais, a saber, a "Lei de Diretrizes e Bases da Educação - LDB", lei no 9.394/96, em específico o art. $36 \S 1^{\circ}$ na qual a referida lei apresenta o ensino de filosofia na educação básica com objetivo de possibilitar ao estudante compreender os conhecimentos filosóficos para fins necessários ao exercício da cidadania. Para Gallo:

a argumentação presente nos PCNEM - que vê na filosofia uma preparação abrangente do indivíduo, fazendo parte de sua introdução no universo da cultura e das técnicas para aí transitar -, prefiro apostar no ensino de filosofia como um fim em si mesmo, para além de qualquer tutela, seja ela cidadã ou moral (GALLO, 2012, p. 22).

Seguindo o pensamento de Gallo, o ensino de filosofia, na educação básica, de acordo com os PCNEM, vem construir uma relação entre homem-sociedade-cultura, enquanto disciplina formativa de sujeitos que agem dentro da sociedade. Porém, pensar o ensino de filosofia nas escolas públicas brasileiras e na atual conjuntura política do país, é pensar a educação filosófica como uma forma de resistência "ao momento presente, momento de contínua aceleração, no qual nada mais é duradouro; e resistência à opinião generalizada, ao jogo daqueles que tudo sabem sobre todas as coisas" (GALLO, 2012, p. 22), e é contra a essa opinião generalizada citada por Gallo que devemos resistir, pois, como diz Deleuze e Guattari: "é da opinião que vem a desgraça dos homens" (1997a, p. 265). Seguindo o pensamento dos filósofos, praticar o exercício filosófico na educação básica é provocar um rasgo no caos, fazendo com que os alunos busquem uma saída da falsa segurança das opiniões; desse modo, ensinar o exercício filosofar nas escolas públicas brasileiras, nos dias de hoje é uma forma de resistência e luta contra as opiniões que vem anunciando colocar o mundo em ordem.

Para Gallo "potencializar a resistência é necessário, [...], explorar a problemática do ensino de filosofia no contexto de uma "educação menor" (GALLO, 2012, p. 25). Em relação à educação, o autor aponta que podemos encontrar duas formas de educação: a educação menorque seria uma educação de empreendimento de militância - e a educação maior - que seria uma educação mais de âmbito político. Nas palavras do autor:

\footnotetext{
${ }^{3}$ Silvio Gallo propõe fazer um deslocamento conceitual para falar de "educação menor" e "educação maior". O autor buscou fazer um jogo de palavras com os conceitos "literatura menor" e "literatura maior". Conceitos estes criados por Deleuze e Guattari em 1975, na qual os filósofos buscam analisar a obra e o pensamento de Franz Kafka. Deleuze e Guattari já vêm nos apresentando e dando tamanha importância ao conceito de "literatura menor" já no titulo da obra, intitulada Kafka: Por um Literatura menor. "Deleuze e Guattari analisaram a obra de Kafka como uma literatura de resistência. Para tanto, criaram os conceitos de 'literatura maior', aquela produzida numa língua estabelecida, segundo os padrões culturais de um povo ou nação, e de 'literatura menor', aquela - como a de Kafka - produzida no contexto de uma língua maior, estabelecida, mas que a subverte, cria nela linhas de fuga, faz dela trincheira de resistência, de minoridade. [...] A obra de Kafka é uma subversão e uma resistência à literatura alemã; em outras palavras, uma "literatura menor" (GALLO, 2012, p. 25-26). Não obstante, os conceitos maior e menor retornam ao pensamento dos filósofos na obra Mil Platôs: No Tratado de Nomadologia vol. 5, texto este em que os autores pensaram a ação política na disjunção aparelho de Estado -maquina de guerra, sedentarismo - nomadismo, em que os autores exploraram em torno dos conceitos de "ciência menor" ou "ciência nômade" e a "ciência maior" ou "ciência régia".
}

JARDIM, Alex Fabiano Correia; OLIVEIRA, Adhemar Santos de. O ensino de filosofia no processo de resistência. Griot : Revista de Filosofia, Amargosa - BA, v.20, n.2, p.332-346, junho, 2020. 
educação maior é aquela do âmbito político de ensino gestadas nos ministérios e secretarias, a dos grandes planos, dos macroplanejamentos, uma educação menor é aquela que se pratica nas salas de aula, entre as quatro paredes, no âmbito pequeno, como resistência, como produção de algo que se coloca para além e para aquém das grandes políticas [...], uma educação menor instala-se no interior de espaço escolar produzido e gerido pela educação maior, mas como um vírus, oferece resistência e roendo por dentro essa educação maior. Uma educação menor é um empreendimento de militância (GALLO, 2012, p. 26).

Porém, para pensar uma educação maior e menor, é preciso pensar também a relação: macropolítica e micropolítica. Seguindo o pensamento deleuziano, toda relação política é, ao mesmo tempo, macropolítica e micropolítica; sendo uma molar e outra molecular. Nas palavras de Deleuze e Guattari: "Toda sociedade, mas também todo indivíduo, são pois atravessados pelas duas segmentaridades ao mesmo tempo: uma molar e outra molecular" (2012a, p. 99). Desse modo, segue os filósofos:

A política opera por macrodecisões e escolhas binárias, interesses binarizados; mas o domínio do decidível permanece estreito. E a decisão política mergulha necessariamente num mundo de microdeterminações, atrações e desejos, que ela deve pressentir ou avaliar de um outro modo. Há uma avaliação dos fluxos de seus quanta, sob as concepções lineares e as decisões segmentárias. Uma página curiosa de Michelet condena Francisco I por ter mal avaliado o fluxo de emigração que empurrava para a França muita gente em luta contra a Igreja: Francisco I viu nisso apenas uma afluência de possíveis soldados, ao invés de perceber aí um fluxo molecular de massa de que a França teria podido tirar proveito, assumindo a liderança de uma Reforma diferente daquela que se produziu. Os problemas se apresentam sempre desse jeito. Boa e má, a política e seus julgamentos são sempre molares, mas é molecular, com suas apreciações, que a "faz" (DELEUZE; GUATTARI, 2012a, p. 111-112 - grifo nosso).

Para se pensar a relação macropolítica e micropolítica, os filósofos pensaram, primeiro, que as grandes decisões políticas partem do âmbito molar. Porém, as decisões da macropolítica devem passar necessariamente pelas apreciações moleculares; é delas que a micropolítica se faz forte. Assim, a educação maior seria uma educação molar, a educação das grandes políticas do Ministério da educação e das Secretárias de Educação Estadual e Municipal, e a educação menor, educação molecular, é a educação da pequena política das salas de aulas. Não obstante, Gallo identificou também dois tipos de professores nessa binaridade educacional: o professorprofeta identificado na macropolítica e o professor-militante identificado na micropolítica.

Para o autor, no âmbito da educação moderna, o professor-profeta seria aquele professor crítico e consciente das suas relações sociais, que profetiza uma reforma social pela educação, possibilitando, assim, um "novo mundo", portanto, o professor-profeta anuncia as possibilidades e as transformações sociais e políticas do indivíduo por meio da educação. Nessa perspectiva, Gallo nos apresenta o pensamento do filósofo francês René Schérer que, em sua obra Émile Perverti ${ }^{4}$, faz uma dura crítica a esse sistema de educação moderna e ao processo de prolongamento de escolarização dos estudantes, pois, para o filósofo, esse sistema é uma armadilha que prende os estudantes a um modelo disciplinar da educação maior. Gallo cita Schérer:

A escola desempenha um papel evidentemente essencial, pelo diferentemente que ela impõe a toda atividade inserida na vida social. O prolongamento da escolaridade,

\footnotetext{
4 "Emílio Pervertido" obra provocante, publicada em 1974 e que tem como alvo a obra Emílio do filósofo Jean JaquesRousseau, na qual Schérerapresenta duras críticas ao sistema educacional moderno.
}

JARDIM, Alex Fabiano Correia; OLIVEIRA, Adhemar Santos de. O ensino de filosofia no processo de resistência. Griot : Revista de Filosofia, Amargosa - BA, v.20, n.2, p.332-346, junho, 2020. 
considerado por todas as consciências progressistas como uma conquista da civilização e libertação do jovem contra a dura lei do trabalho, possibilidade de viver um tempo mais longo sem o encargo das "pesadas" responsabilidades do homem feito, eis aí a pior das manifestações. Eis aí a armadilha. E por essa armadilha, bem ou mal, ele se deixa prender, pois de fato o trabalho é alienado e absurdo, e para ele é uma vantagem real que sua entrada na forma adulta de existência burguesa (ou operária, o que é a mesma coisa) seja adiada o máximo possível. Compreende-se muito bem essa atitude, numa sociedade que considera o estado de adulto como uma parada do desenvolvimento do indivíduo, além do qual nada resta a esperar [...] (SCHÉRER 2006, apud GALLO, 2016b, p. 40)

Seguindo as colocações de Schérer, podemos observar que a educação moderna, vinculada às ideias do professor-profeta, vem contribuir com o avanço das opiniões, fazendo com que os estudantes adotem tais opiniões como verdadeiras e se afastem do campo do pensamento. Desse modo, Gallo destaca que, para o filósofo, não há esperança na escola e que devemos destruir o que ele definiu como "utopia pedagógica” moderna. Para Schérer há um

\footnotetext{
Duplo princípio que orienta o círculo vicioso do poder que designa como utopia pedagógica, quer dizer, a ideia de uma reforma social pela educação, a ideia de que seria possível formar um homem capaz de construir uma sociedade mais bem instruída - ou um homem mais bem dotado, capaz de construir uma sociedade diferente. Assim, a utopia pedagógica é apenas uma outra face da utopia política que, por sua vez, está sempre não só acompanhada por pedagogia, mas ela própria é pedagógica; eis o que aliás, já sabemos desde Platão. Essa maneira de falar ainda seria equívoca ao sugerir a ideia de que a pedagogia pudesse deixar de ser utópica. Ora, trata-se, precisamente, de caracterizar a pedagogia, na generalidade de sua proposta, como utopia. (SCHÉRER 2006, apud GALLO, 2016b, p. 41).
}

Ora, lutar contra uma proposta de desescolarização total de uma sociedade pensada por Schérer é pensar uma pedagogia anarquista, mas, "num anarquismo político especial, de perversão e não de destruição, anarquismo que, sobre a ideia de irredutibilidade do pequeno ao grande" (ZOURABICHVILI, 2016, p. 30), fundando, assim, o conceito de resistência no âmbito da educação menor e é nesse sistema de educação que Gallo identifica o outro tipo de professor: professor militante.

O professor militante é diferente do professor-profeta, pois ele não anuncia a possibilidade do novo, ele procura viver as situações de dentro das situações vividas, produzindo, assim, a possibilidade do novo, como pensou Deleuze e Guattari (1997a). O professor militante é aquele que luta contra as forças do caos. Para Gallo, "seria aquele que procura viver a miséria do mundo, [...] a miséria de seus alunos, seja ela qual miséria for" (GALLO, 2016a, p. 61). É como se esse tipo de professor mergulhasse no rio do Aqueronte para viver as misérias dos seus alunos e, com isso, voltar do fundo desse rio com a possibilidade de construir algo coletivo. Portanto, para Gallo

[...] o profeta seja mais aquele que anuncia do ponto de vista individual. Mas o militante tem sempre uma ação coletiva; a ação do militante nunca é uma ação isolada. Então, o professor militante seria aquele que, vivendo as misérias dos alunos ou a miséria da situação social da qual ele participa, procuraria, coletivamente, ser um vetor da produção de superação, de condições de superação dessa miséria, ser um vetor de libertação, de possibilidade de libertação. Se o professor-profeta é aquele que age individualmente para mobilizar multidões, o professor militante é aquele que age coletivamente, para tocar a cada um dos indivíduos (GALLO, 2016a, p. 61). 
Não obstante o conceito de literatura menor, pensado por Deleuze e Guattari, adquire um valor coletivo, a educação menor é levada a adquirir também um valor coletivo, que irá tomar conta de toda a comunidade. Seguindo o pensamento de Deleuze e Guattari, a literatura menor de Kafka é uma desterritorialização da língua ${ }^{5}$ e, contudo, educação menor passa a ser uma desterritorialização dos processos educativos. Nessa perspectiva, Gallo diz:

Uma educação menor é um ato de revolta e resistência. Revolta contra os fluxos instituídos, resistência às políticas impostas; sala de aula como trincheiras, como a toca do rato, o buraco do cão. Sala de aula com espaço a partir do qual traçamos nossas estratégias, estabelecemos nossa militância, produzindo um presente e um futuro aquém ou para além de qualquer política educacional (GALLO, 2016a, p. 64-65).

A educação menor vem seguir os fluxos de um devir6-aluno, portanto a presença do exercício do filosofar na escola é uma linha de fuga, que se revela como Deleuze e Guattari (1997b) definiram como um devir-minoritário, uma potência, uma micropolítica ativa, pois ela vai de encontro à grande política das instituições públicas de ensino, nas quais querem incluir o ensino de filosofia com o único propósito de cumprir uma necessidade 'burocrática'. Portanto, o que observamos nas escolas é que a filosofia é trabalhada e pensada pela educação maior, fazendo com que ela seja voltada para a erudição ou para o exercício da cidadania. Não obstante, Nietzsche, em seu texto: Escritos sobre a educação, já vinha fazendo uma denúncia acerca da forma de se ensinar filosofia nas escolas e universidades alemãs, no século XIX. Nas palavras de Nietzsche:

E afinal de contas, o que importa a nossos jovens a história da filosofia? Devem eles ser desencorajados a ter opiniões, diante do montão confuso de todas as que existem? Devem eles também ser ensinados a entoar cantos jubilosos pelo muito que já tão magnificente construímos? Devem eles por ventura aprender a odiar e desprezar a filosofia? E se ficaria quase tentado a pensar nesta última alternativa, quando se sabe como, por ocasião dos seus exames de filosofia, os estudantes têm de se martirizar para imprimir nos seus pobres cérebros as ideias mais loucas e mais impertinentes do espírito humano junto com as mais grandiosas e as mais difíceis de captar. A única crítica de uma filosofia que é possível e que além disso é também a única que demonstra algo, quer dizer, aquela que consiste em experimentar a possibilidade de viver de acordo com ela, esta filosofia jamais foi ensinada nas universidades: sempre se ensinou apenas a crítica das palavras pelas palavras. E agora, que se imagine uma mente juvenil, sem muita experiência de vida, em que são encerrados confusamente cinquenta sistemas reduzidos a fórmulas e cinquenta críticas destes sistemas - que desordem, que barbárie, que escárnio quando se trata da educação para a filosofia! De fato, todos concordam em dizer que não se é preparado para filosofia, mas somente para uma prova de filosofia, cujo resultado, já se sabe, é normalmente que aquele que sai desta prova - eis que é mesmo uma provocação confessa para si com um profundo suspiro de alívio: Graças a Deus, não sou um filósofo, mas um cristão e um cidadão do meu país! (NIETZSCHE, 2003, p. 212-213).

\footnotetext{
${ }^{5}$ Deleuze e Guattari enumeram três características da literatura menor. A primeira característica é quando uma língua é afetada de um forte coeficiente de desterritorialização; a segunda, que tudo na literatura menor é político; e, a terceira é que tudo toma valor coletivo. Desse modo, para Deleuze e Guattari:“As três características da literatura menor são desterritoralização da língua, a ligação do individual no imediato-político, o agenciamento coletivo de enunciação. É o mesmo que dizer que 'menor' não qualifica mais certas literaturas, mas as condições revolucionárias de toda literatura no seio daquela que se chama grande (ou estabelecida)" (DELEUZE, GUATTARI, 2017, p. 39).

${ }^{6}$ Para Deleuze e Guatttari: "um devir minoritário só existe por meio de um termo médium e de um sujeito desterritorializado que são como seus elementos. Só há sujeito do devir como variável desterritorializada da maioria, e só há termo medium do devir como variável desterritorializante de uma minoria. $O$ que nos precipita num devir pode ser qualquer coisa, a mais inesperada, a mais insignificante" (1997b, p. 89 - grifo dos autores).
}

JARDIM, Alex Fabiano Correia; OLIVEIRA, Adhemar Santos de. O ensino de filosofia no processo de resistência. Griot : Revista de Filosofia, Amargosa - BA, v.20, n.2, p.332-346, junho, 2020. 
Desse modo, Nietzsche faz uma dura crítica de como o ensino de filosofia estava sendo trabalhado e pensado, na Alemanha do século XIX, pois, para o filósofo, a forma utilizada para o ensino da filosofia só servia para produzir o afastamento do aluno do exercício do filosofar ou do campo do pensamento. Assim, o ensino de filosofia era um ensino enciclopedista, com uma erudição falsa. Dessa forma, podemos observar que o ensino de filosofia denunciado por Nietzsche, no séc. XIX, em nada se diferencia do ensino de filosofia adotado pelas diretrizes educacionais brasileiras, pois elas estão sempre nos dizendo o que ensinar; como ensinar; para quem ensinar; e, por que ensinar? Para Gallo, essa educação maior é desenvolvida para controlar as minorias, como destaca o autor:

A educação maior procura construir-se como uma imensa máquina de controle, uma máquina de subjetivação, de produção de indivíduos em série. Não consigo aqui me livrar das fortes imagens do filme The Wall, de Allan Parker, quando sob os sons de Another brick in the wall, do Pink Floyd, a escola inglesa é mostrada com uma imensa máquina que transforma crianças em bonecos sem face e que pouco a pouco são trituradas num imenso moedor de carne. Cada estudante é nada mais, nada menos, do que um outro tijolo no muro; ou uma outra engrenagem na máquina. Mas o princípio da educação maior como máquina de controle pressupõe que ao ensino corresponda uma aprendizagem. (GALLO, 2016a, p. 65).

Porém, na sequência do filme The Wall de Allan Parker, as crianças se revoltam, e destroem a máquina de controle, cantando os versos da música "Another brick in the wall - parte 2": "we don't need no education/We don't need no thought control/No dark sarcasm in the classroom/Teachers leave them kids alone ${ }^{7 "}$, desse modo, a cena e a música que mostram as crianças se rebelando e fugindo de qualquer sistema de controle, como um forma de poder de resistência, leva-nos a compreender o que Deleuze e Guattari vem nos dizer sobre o conceito de 'máquina de guerra'. Para os filósofos, tal conceito é uma 'linha de fuga ${ }^{9}$ ', que atesta toda a resistência, pois ela deriva de um devir, um "devir-revolucionário", dado que a máquina de guerra se relaciona de forma positiva com o agenciamento social. A esse agenciamento, os filósofos chamaram de 'nomadismo'. Sobre a máquina de guerra, Deleuze afirmou que:

Em suma, a linha de fuga converte-se em linha de abolição, destruição das outras e de si mesma, a cada vez que ela é traçada por uma máquina de guerra. E é esse o perigo especial desse tipo de linha, que se mistura, mas não se confunde com os perigos precedentes. A ponto de, a cada vez que uma linha de fuga acaba em linha de morte, nós não invocarmos uma pulsão de interior do tipo "instinto de morte", invocamos ainda um agenciamento de desejo que põe em jogo uma máquina objetiva ou extrinsecamente definível. Não é, portanto, por metáfora que, a cada vez que alguém destrói os outros e

\footnotetext{
${ }^{7}$ “Nós não precisamos de educação / Nós não precisamos de controle de pensamento / Nenhum sarcasmo escuro na sala de aula / Professores, deixem as crianças em paz!" (Tradução nossa)

${ }^{8}$ Para François Zourabichvili Linha de fuga é o "conceito que define a orientação prática da filosofia de Deleuze. Observa-se, em primeiro lugar, uma dupla igualdade: linha = fuga, fugir = fazer fugir. $O$ que define uma situação é uma certa distribuição dos possíveis, o recorte espaço-temporal da existência (papéis, funções, atividades, desejos, gostos, tipos de alegrias e dores, etc.). Não se trata tanto de ritual - de repetição morna, de alternância demasiado regulada, de exiguidade excessiva do campo de opções - mas da própria forma, dicotômica, da possibilidade: ou isso ou aquilo, disjunções exclusivas de todas as ordens (masculino - feminino, adulto - criança, humano - animal, intelectual - manual, trabalho - lazer, branco - preto, heterossexual - homossexual, etc.) que estriam previamente percepção, a afectividade, o pensamento, encerrando a experiência em formas totalmente prontas, inclusive de recusa e de luta. [...] Em todo caso, expressa nesses termos, a prática deleuze-guattariana cairia na armadilha de outra dicotomia infamante: ordem/desordem. Ora, a desordem bem compreendida não significa o vazio ou o caos, mas antes um "corte" no caos, seu enfrentamento mais que sua negação em nome de presumidas formas naturais. Esses vetores de desorganização ou de "desterritorialização" são precisamente designadas como linhas de fuga" (ZOURABICHVILI, 2004, p. 29-30).
}

JARDIM, Alex Fabiano Correia; OLIVEIRA, Adhemar Santos de. O ensino de filosofia no processo de resistência. Griot : Revista de Filosofia, Amargosa - BA, v.20, n.2, p.332-346, junho, 2020. 
destrói a si mesmo, ele inventou sobre sua linha de fuga sua própria máquina de guerra (DELEUZE, PARNET, 1998, p. 165).

[...] definimos a "máquina de guerra" como um agenciamento linear que se constrói sobre linhas de fuga. Nesse sentido, a máquina de guerra não tem absolutamente por objeto a guerra; ela tem por objeto um espaço muito especial, espaço liso, que ela compõe, ocupa e propaga. O nomadismo é precisamente esta combinação máquina de guerra-espaço liso. (DELEUZE, 1992, p. 47).

Portanto, a educação menor seria a linha de fuga. Ela age por brechas, fazendo emergir possibilidades dos estudantes escaparem de qualquer controle. Ela propõe resistência, ela produz a diferença. A educação menor vem desterritorializar qualquer plano de controle da educação maior, provocando um vazamento no sistema ou, como Deleuze pensou, um furo no cano. Traçando uma linha, a educação menor descobre mundos por meio de uma longa fuga. Já o professor militante é a máquina de guerra, pois, ele constrói sobre as linhas de fuga novos métodos de ensino de filosofia, atividades que fazem apelo à sensibilidade dos estudantes, considerando o seu universo cultural, "neste aspecto, a aprendizagem coloca-se para além de qualquer controle." (GALLO, 2016a, p. 66).

Para Deleuze, é na sensibilidade que está a potência da aprendizagem. Só se apreende o que pode ser sentido. Deleuze chamou esse aprender de 'educação dos sentidos'. "Mas o que significa aprender?",o filósofo afirma que:

Nunca se sabe de antemão como alguém vai aprender - que amores tornam alguém bom em latim, por meio que encontros se é filósofo, em que dicionário se aprende a pensar. Os limites das faculdades se encaixam uns nos outros sob a forma partida daquilo que traz e transmite a diferença. Não há método para encontrar tesouros nem para aprender, mas um violento adestramento, uma cultura ou Paideia que percorre inteiramente todo indivíduo (um albino em que nasce o ato de sentir na sensibilidade, um afásio em que nasce a fala na linguagem, um acéfalo em que nasce pensar no pensamento). $O$ método é o meio de saber quem regula a colaboração de todas as faculdades; portanto, ele é manifestação de um senso comum ou a realização de um Cogiatatio natura, pressupondo uma boa vontade como uma "decisão premeditada" do pensador. Mas a cultura é o movimento de aprender, a aventura do involuntário, encadeando uma sensibilidade, uma memória, depois um pensamento, com todas as violências e crueldades necessárias, dizia Nietzsche, juntamente para "adestrar um povo de pensadores", "fazer um adestramento do espírito". [...] Aprender é tão somente o intermediário entre não-saber e saber, a passagem viva de um ao outro. Pode-se dizer que aprender, afinal de contas, é uma tarefa infinita, mas esta não deixa de ser rejeitada para o lado das circunstâncias e da aquisição, posta para fora da essência supostamente simples do saber como inatismo, elemento a priori ou mesmo Idéia reguladora. E, finalmente, a aprendizagem está, antes de mais nada, do lado do rato no labirinto, ao passo que o filósofo fora da caverna considera somente o resultado - o saber - para ele extrair os princípios transcendentais. (DELEUZE, 2006b, p. 237-238).

Aprendizagem é algo que faz o estudante escapar de qualquer controle, pois é na aprendizagem que está a resistência, ela também é a linha de fuga, pois desterritorializa os princípios da educação maior. E, é seguindo o pensamento de Deleuze, que o professor deve exercer, no espaço das salas de aula, suas ações de micropolítica, criando trincheiras e estratégias para que seus alunos não caiam no controle da educação maior, pois, assim como seus alunos, o professor também se encontra no processo de aprendizagem. Desse modo, o professor escava seus buracos como um cão, a cada aula, pois, segundo Deleuze,

[...] as aulas são algo muito especial. Uma aula é um cubo, ou seja, um espaço-tempo.

Muitas coisas acontecem numa aula. [...] Uma aula é algo que se estende de uma semana

JARDIM, Alex Fabiano Correia; OLIVEIRA, Adhemar Santos de. O ensino de filosofia no processo de resistência. Griot : Revista de Filosofia, Amargosa - BA, v.20, n.2, p.332-346, junho, 2020. 
a outra. É um espaço e uma temporalidade muito especiais. Há uma sequência. Não podemos recuperar o que não conseguimos fazer. Mas há um desenvolvimento interior numa aula. $E$ as pessoas mudam entre uma semana e outra. $O$ público de uma aula é algo fascinante. (DELEUZE, Abecedário, letra P).

Desse modo, as aulas de filosofia têm de ser a linha de fuga, a resistência dos estudantes; e o professor tem que ser a própria máquina de guerra, sabotar a máquina de controle, criar novas possibilidades para o ensino de filosofia. Não obstante, pensar em uma didática que pode dar conta do ensino de filosofia ou do aprender a filosofar é algo que nos escapa, pois o aprendizado em filosofia está para além de qualquer metodologia de ensino e de controle. "O ensino de filosofia não pode ser abarcado por uma didática geral, não pode ser equacionado unicamente como uma questão pedagógica, porque há algo de específico na filosofia" (GALLO, 2012, p. 53). E é esse algo específico da filosofia que a faz não ser uma ciência, religião ou opinião. $O$ ensino de filosofia necessita de uma didática específica, que ultrapassa qualquer questão estritamente pedagógica.

Gallo identifica as três especificidades que caracterizam a filosofia. Para o autor, a filosofia

1) trata-se de um pensamento conceitual: enquanto saber, ela é sempre produto de pensamento, é uma experiência de pensamento. Mas o que caracteriza a filosofia [...] é que ela é uma experiência de pensamento que procede por conceitos, que cria conceitos, à diferença da ciência e da arte;

2) apresenta um caráter dialógico: ela não se caracteriza como um saber fechado em si mesmo, uma verdade dogmática, mas como um saber que se experimenta, que se confronta, consigo mesmo e com os outros, que se abre ao diálogo com outros saberes, um saber aberto e em construção;

3) possibilita uma postura de crítica radical: a atitude filosófica é a da não conformação, do questionamento constante, da busca das raízes das coisas, não se contentando com respostas prontas e sempre colocando em xeque as posturas dogmáticas e as certezas apressadas. (GALLO, 2012, p. 54).

Contudo, as características 'caráter dialógico e postura de crítica radical' são também encontradas em outras formas de saber, o que faz a filosofia ser algo diferente das ciências e das artes é que ela trata, especificamente, com o conceito como foi apontando por Deleuze e Guattari em $O$ que é a filosofia? - para eles, a filosofia é a disciplina que cria conceitos. "Criar conceitos novos é objetivo da filosofia." (DELEUZE, GUATTARI, 1997a, p. 13).

Deleuze e Guattari identificaram três períodos acerca do conceito - enciclopédia, pedagogia e formação profissional - e também identificaram que a filosofia cruzou com muitos rivais, destacando os que transformaram a natureza dos conceitos, ora em representações coletivas, ora em concepções do mundo criados pelos povos. Para os filósofos, os dois grandes inimigos da filosofia como disciplina que cria conceitos foram: os pós-kantianos, em especial Hegel, e o marketing. Nesses, o conceito passa a servir a um espírito absoluto ou se coloca a serviço do comércio.

Para Deleuze e Guattari, os pós-kantianos pensaram o conceito como uma forma de realidade filosófica, a qual gira em torno de uma enciclopédia universal. E é Hegel, segundo os filósofos (1997a), quem mostrava que o conceito nada tinha a ver com a ideia geral ou abstrata; e nem com a Sabedoria in-criada, assim sendo, o conceito não dependeria da filosofia. Como afirmam Deleuze e Guattari:

Foram os pós-kantianos que mais deram atenção, neste sentido, ao conceito como realidade filosófica, notadamente Schelling e Hegel. Hegel definiu poderosamente os conceitos pelas Figuras de sua criação e os Momentos de sua autoposição: as figuras

JARDIM, Alex Fabiano Correia; OLIVEIRA, Adhemar Santos de. O ensino de filosofia no processo de resistência. Griot : Revista de Filosofia, Amargosa - BA, v.20, n.2, p.332-346, junho, 2020. 
tornaram-se pertenças do conceito, porque constituem o lado sob o qual o conceito é criado por e na consciência, por meio da sucessão de espírito, enquanto os momentos erigem o outro lado, pelo qual o conceito se põe a si mesmo e reúne os espíritos no absoluto do Si. Hegel mostrava, assim, que o conceito nada tem a ver com a idéia geral ou abstrata, nem tampouco com a Sabedoria in-criada, que não dependeria da própria filosofia. Mas era ao preço de uma extensão indeterminada da filosofia, que não deixava subsistir o movimento independente das ciências e das artes, porque reconstituía universais com seus próprios momentos, e só tratava os personagens de sua própria criação como figurantes fantasmas. Os pós-kantianos giravam em torno de uma enciclopédia universal do conceito, que remeteria sua criação a uma pura subjetividade [...] (DELEUZE, GUATTARI, 1997a, p. 20-21 grifo dos autores).

Hegel, portanto, vem construir o conceito como uma reconciliação entre o singular e o universal, uma vez que, para ele, os conceitos $^{9}$ são figuras de criação e momentos de autoposição, e se constituindo como momentos de um espírito absoluto que se manifesta vez ou outra, valorizando, assim, como uma extensão infinita da filosofia.

Para Deleuze e Guattari, Hegel permanece numa historicidade, à medida que toma a história como uma forma de interioridade, na qual o conceito desenvolve ou desvela em seu destino; ele repousa na abstração do elemento histórico tornado circular. Deleuze, então, tenta libertar a filosofia e o conceito de toda ideia de um movimento de um espírito cujo destino é atravessar a história. Para que essa libertação ocorra, Deleuze e Guattari inseriram a noção de acontecimento e a concepção de tempo para libertar o conceito da subordinação histórica. Segundo Zourabichvili, é o acontecimento que colocará em crise a ideia de história, pois "o que acontece, enquanto acontece e rompe com o passado, não pertence à história e não poderia ser explicado por ela." (ZOURABICHVILI, 2016, p. 48).

Nesse sentido, Deleuze, em sua obra Lógica do Sentido (2011), destaca duas leituras do tempo para se pensar na efetuação do acontecimento. O tempo Aiôn que é o tempo das transformações dos acontecil7mentos incorporais e o tempo Cronos que é o tempo da circularidade e do acidente, um tempo de "historicismo", sendo inseparável dos corpos que preenchiam como causa e matéria. Seguindo o pensamento deleuziano, Zourabichvili diz: "enfim, a distinção de Aiôn e de Cronos, do acontecimento e de sua efetuação, evita um puro e simples dualismo do espírito e do corpo, pois as efetuações físicas já implicam o que difere delas por natureza (o acontecimento)" (ZOURABICHVILI, 2016, p. 118). Sousa Dias também nos diz que:

O acontecimento é uma virtualidade, é um puro virtual. É um devir, um movimento infinito, infinitivo. Por isso é lhe próprio esquivar o presente, cindi-lo em duas linhas divergentes ilimitadas, passado e futuro, eventum tantum ao mesmo tempo sempre já-aí e ainda-não. Daí os dois tempos, Cronos e Aiôn, distinguidos pelo estoicismo. O tempo dos corpos, das suas misturas, dos seus acidentes como efectuação dos acontecimentos é o presente cósmico como unidade do Todo: só o presente existe no tempo, o passado é só um antigo presente, como o futuro, um presente por vir (Cronos). Mas o tempo dos acontecimentos virtuais é outro: só o passado e o futuro insistem no tempo e dividem ao infinito cada presente (Aiôn) (DIAS, 1995, p. 96).

\footnotetext{
${ }^{9}$ La Salvia em seu texto "Problemas de uma pedagogia do conceito: pensando um ensino de filosofia", destaca que, para Hegel "o conceito é criado, mas por uma pura subjetividade que se conecta a outras subjetividades em uma sucessão de espíritos na consciência do espírito absoluto. Ou seja, cada criação filosófica genial de conceitos são momentos que fazem parte do movimento de um espírito absoluto cujo destino é atravessar a história" (2016, p. 54).
} 
Não obstante, para La Salvia enquanto "o cronos hegeliano devora seus conceitos anteriores para alcançar o espírito absoluto, o Aion deleuzeano opera a cada vez, nos encontros, como aquilo que salta e afeta, provoca mudanças" (LA SALVIA, 2016, p. 56). Portanto, seguindo o pensamento deleuziano, podemos afirmar que os conceitos são acontecimentos e não relativos. Desse modo, a questão do acontecimento e a concepção do tempo, para La Salvia, (2016) fazem com que Deleuze e Guattari fujam dos criadores de conceitos como manifestação de um espírito absoluto.

Já o segundo inimigo - o marketing -desenvolve a ideia de conceito como formação profissional, identificado por Deleuze e Guattari como a mais insolente e calamitosa. Para os filósofos, é com essa ideia que chegamos ao fundo do poço da vergonha, pois a informática, o design, a publicidade e todas as disciplinas da comunicação se apoderaram da palavra conceito e acontecimento como marketing do comércio de um capitalismo universal. Nas palavras de Deleuze e Guattari:

O marketing reteve a idéia de uma certa relação entre o conceito e o acontecimento; mas eis que o conceito se tornou o conjunto das apresentações de um produto (histórico, científico, artístico, sexual, pragmático...), e o acontecimento, a exposição que põe em cena apresentações diversas e a "troca de idéias" à qual supostamente dá lugar. (DELEUZE, GUATTARI, 1997a, p. 19 - grifo dos autores).

Nesse sentido, Deleuze e Guattari apontam que o marketing é um rival poderoso da filosofia, pois, segundo os filósofos, os programadores de informática e os publicitários apoderaram-se da própria palavra "conceito", chegando a dizer: "é nosso negócio, somos nós os criativos, nós somos os conceituadores!" (DELEUZE, GUATTARI, 1997a, p.19 - grifo dos autores). Não obstante, Deleuze e Guattari ainda destacam que eles se intitulam como sendo os verdadeiros amigos do conceito: "somos nós os amigos do conceito, nós os colocamos em computadores. Informações e criatividade, conceito e empresa" (DELEUZE, GUATTARI, 1997a, p. 19 - grifo do autor). Na obra Conversações Deleuze destaca que:

Hoje é a informática, a comunicação, a promoção comercial que se apropriaram dos termos "conceito" e "criativo", e esses "conceituadores" formam uma raça atrevida que exprime o ato de vender como o supremo pensamento capitalista, o cogito da mercadoria" (DELEUZE, 1992, p. 170 - grifo nosso).

O marketing, portanto, transformou a palavra "conceito" em apresentações de um produto; e o "acontecimento" em exposições diversas do produto que se pode vender. O vendedor ou o apresentador se transformaram também em um personagem conceitual, ou melhor, transformaram-se em "filósofos". Como afirmam Deleuze e Guattari:

O simulacro, a simulação de um pacote de macarrão tornou-se o verdadeiro conceito, e o apresentador-expositor do produto, mercadoria ou obra de arte, tornou-se o filósofo, o personagem conceitual ou o artista" (DELEUZE, GUATTARI, 1997a, p. 19).

O objetivo do marketing é "criar" conceitos que afetem os consumidores com a sua exposição, enquanto o acontecimento conduz à compra do macarrão. O marketing cria um consenso universal de convencimento de compra de determinado produto, estabelecendo, assim, um padrão de consumo. Para Deleuze, o que os publicitários querem é "fundar um 'consenso', mas o consenso é uma regra ideal de opinião que nada tem a ver com filosofia. Dir-se-ia que se trata aí de uma filosofia-propaganda." (DELEUZE, 1992, p. 190). La Salvia destaca que:

JARDIM, Alex Fabiano Correia; OLIVEIRA, Adhemar Santos de. O ensino de filosofia no processo de resistência. Griot : Revista de Filosofia, Amargosa - BA, v.20, n.2, p.332-346, junho, 2020. 
[...] a época atual cria uma "imagem comercial do pensamento", basta considerar um pensamento sucessivamente afetado por comerciais que levam a emitir opiniões que são um consenso sobre determinados produtos, como "cerveja que desce redondo", "dedicação total a você"... ou ainda, associar ideias e criar uma imagem comercial para alguns conceitos, como a "liberdade" que certo automóvel pode lhe dar, ou a "sensação" que determinado macarrão pode lhe fazer sentir. (LA SALVIA, 2016, P. 60).

Portanto, para Deleuze e Guattari “[...] é doloroso descobrir que 'Conceito' designa uma sociedade de serviços e de engenharia informática." (DELEUZE, GUATTARI, 1997a, p. 19). Se é isso a que chamamos de filosofia, compreende-se que o marketing se apodera do conceito, e que o publicitário se apresenta como o conceituador e pensador por excelência. Porém os grandes publicitários são aqueles que não só vendem um produto, mas são aqueles que transformam o nome do produto em um conceito que afeta o consumidor e o faz comprar. Como por exemplo: "BomBril para esponja de aço; Cotonete para haste flexível plástica com algodões nas duas extremidades; Gillette para lâminas de barbear; Band-aid para curativo; Yakult para leite fermentado; etc.". Desse modo, os publicitários e os programadores de informática "têm uma função meramente social, dialógica e dóxica: eles são a encarnação da sociedade de controle" 10 (BIANCO, 2005, p. 1305 - grifo nosso).

Entretanto, o marketing não chega de fato a se tornar uma grande ameaça à filosofia, pois ela não consegue realmente captar o acontecimento. Não chega, assim, ao poder noético e criativo da arte, ciência e filosofia. Ademais, para Dias "só a arte pode, de facto, fazer sentir o acontecimento, dar-lhe uma evidência sensível, o poder do percepto e do afecto" (DIAS, 1995, p. 97).

Cabe à filosofia e a arte dar uma lição de criatividade e acontecimentalidade aos "pseudocriadores", ou como Deleuze definiu em Imagem-Tempo dar "uma lição pedagógica" (DELEUZE, 2007, p. 298). Ora, a ideia de conceito e de acontecimento deve ser pensada de uma forma pedagógica ou como Deleuze e Guattari definiram, de uma pedagogia do conceito $^{11}$. A pedagogia do conceito, segundo os filósofos, vem "analisar as condições de criação como fatores de momentos que permanecem singulares" (DELEUZE, GUATTARI, 1997a, p. 21). Desse modo, a pedagogia do conceito vem impedir o estudante de cair no niilismo da doxa dos discursos pseudo-filosóficos. Giuseppe Bianco diz que:

Se, como dizia Nietzsche, a tarefa dos pensadores é a de recolher as flechas lançadas por outros filósofos, então, nas condições de nosso presente e do nosso tempo, é nosso dever nos perguntar se uma "pedagogia do conceito" está a altura dos desafios atuais. Cabe a nós estabelecer o quanto essa concepção da filosofia enquanto disciplina criadora e pedagógica pode realmente fazer frente às grandes potências do marketing, do jornalismo, da publicidade, como máquina de produção de acontecimentos banais. (BIANCO, 2005, p. 1305).

Desse modo, levantamos a seguinte questão: como a filosofia, essa velha senhora, poderia alinhar-se com os jovens frente às grandes potências do marketing? Para combatermos esses

\footnotetext{
${ }^{10}$ Deleuze em Conversações indica que não vivemos mais em sociedade disciplinar com foi pensado por Faucault. Para Deleuze, a sociedade disciplinar ficou para trás, pois agora estamos vivendo em uma sociedade de controle, controlada pelo fluxo continuo das comunicações instantâneas. Ele postura que o que identificava a sociedade disciplinar era a assinatura do indivíduo e o número de matrícula que indicava sua posição, já na sociedade de controle, o essencial é a cifra e uma senha. Enquanto a sociedade disciplinar é regulada por palavras de ordem, na sociedade de controle a linguagem é numérica do controle da cifra, marcando, assim, a informação ou a rejeição. O marketing se torna, portanto, o instrumento de controle social.

${ }^{11}$ Deleuze, ao falar da pedagogia do conceito, não está se referindo a uma prática pedagógica que pretende utilizar o conceito como um instrumento de ensino-aprendizagem para uma prática do ensino de filosofia. Diferente dessa perspectiva, Deleuze se refere a um tipo particular de conceito, portanto, não é o conceito que é da pedagogia, mas sim, a pedagogia que é do conceito.
}

JARDIM, Alex Fabiano Correia; OLIVEIRA, Adhemar Santos de. O ensino de filosofia no processo de resistência. Griot : Revista de Filosofia, Amargosa - BA, v.20, n.2, p.332-346, junho, 2020. 
grandes inimigos da filosofia, a pedagogia do conceito vem trazer consigo uma indispensável mensagem de resistência da filosofia diante do pensamento de formação profissional.

Ao se pensar na atual situação da filosofia e na situação de uma prática de ensino de filosofia, podemos observar o quanto anda mal o exercício do pensamento dos nossos jovens estudantes. Em uma das suas entrevistas em Conversações, Deleuze diz: "se hoje o pensamento anda mal é porque, sob o nome de modernidade, há um retorno às abstrações, reencontra-se o problema das origens" (DELEUZE, 1992, p. 151). Portanto, para que possamos escapar dos inimigos apontados anteriormente e retirar os jovens estudantes do campo da doxa (opinião) e recolocá-los no campo do pensamento, devemos pensar em um ensino de filosofia na perspectiva da filosofia da diferença e o conceito como acontecimento, pois, seguindo o pensamento deleuzeguattariano, o pensamento sempre nasce a partir de um encontro com alguma coisa e este "alguma coisa" é o que chamamos de acontecimento. Trata-se de um signo, um enunciado que "alguma coisa" possui e que me afeta enquanto problema. Provoca o pensamento, desse modo, a filosofia sempre está à procura de um intercessor. Segundo Deleuze "o essencial são os intercessores. A criação são os intercessores. Sem eles não há obra" (DELEUZE, 1992, p. 156).

Deleuze, em sua obra Diferença e Repetição, mostra-nos que a forma de aprender deve-se passar pelo exercício da sensibilidade, desse modo, tal exercício faz com que o estudante, na medida em que vai sentindo, desperta-se para a memória e força o pensamento, portanto, para o filósofo, aprender com as intensidades dos sentidos é desenvolver uma "educação dos sentidos". (DELEUZE, 2006b, p. 237). A partir dessa ideia, Deleuze desenvolveu o que ele chamou de 'pedagogia dos sentidos'.

\begin{abstract}
Uma pedagogia dos sentidos volta-se para este objetivo e integra o "transcendentalismo". Experiências farmacodinâmicas, ou experiências físicas como a vertigem, aproximam-se disso: elas nos revelam esta diferença em si, esta profundidade em si, esta intensidade em si, no momento original em que ela não é mais qualificada nem extensa. Então, o caráter dilacerante da intensidade, por mais frágil que seja seu grau, restitui-lhe seu verdadeiro sentido: não antecipação da percepção, mas limite próprio da sensibilidade, do ponto de vista de um exercício transcendente (DELEUZE, 2006b, p. 333-334).
\end{abstract}

Traçar esta ideia de criação e aprendizagem a partir do encontro com os signos sensíveis vem exigir espaços diferentes de aprendizagens e diferentes soluções criadoras no campo problemático do pensamento gerado pelos signos. Desse modo, podemos compreender a noção de pedagogia do conceito, pois ela busca a criação e a aprendizagem, partindo do ato de criação de conceito.

Dessa maneira, a criação de conceitos é uma atividade filosófica e os conceitos são os objetos da filosofia. Deleuze e Guattari destacam que "sob uma forma voluntária escolar, Fréderic Cossuta propôs uma pedagogia do conceito muito interessante" (DELEUZE, GUATTARI, 1997a, p. 21). Ademais, Fréderic Cossuta, ao falar do conceito escreveu:

Mas é precisamente o conceito que constitui o intermediário entre a imagem e a forma, entre o vivido e o abstrato. A filosofia faz usos variados do conceito, mas não há filosofia que não se refira a ele, se preciso trabalhando seus limites, no caminho da abstração universalizante (ver o projeto leibniziano de uma "característica universal"). Mas, se a abstração é vazia de sentido, ou se a imagem e o eu se expõem fora de qualquer forma, a filosofia seguramente anuncia sua própria morte. Se filosofia nada mais é do que conceito, é que ela é propriamente reexame e redefinição do conceito. (COSSUTA, 1994, p. $40)$. 
Por fim, cabe ao ensino de filosofia, dar uma lição de criatividade e de acontecimento; uma lição pedagógica aos pseudocriadores (marketing): entrar em combate, buscar uma linha de fuga. $\mathrm{E}$ o professor militante tem que se tornar uma máquina de guerra. Fazer das suas aulas um movimento de resistência; na confiança do que Deleuze escreveu "o próprio combate tem tantas variações que ele pode prosseguir com todos os acidentes do terreno" (DELEUZE, 1992, p. 101); "não cabe temer ou esperar, mas buscar novas armas." (DELEUZE, 1992, p. 220).

Neste sentido, para Gallo,

[...] a filosofia como disciplina curricular não pode estar isolada das demais. Há, sim, uma transversalidade intrínseca da filosofia; mas não no sentido diluidor apresentado PCNs, mas uma transversalidade afirmada com base em seu caráter disciplinar, em sua especificidade no trato com o conceito. (GALLO, 2012, p. 68).

E é pensando em um ensino de filosofia com a utilização da noção da pedagogia do conceito que podemos compreender um processo que consiste em desenvolver o ato do pensar e o ato de criação de conceitos, proporcionando uma alternativa na forma de ensinar filosofia para, assim, tentar libertar os alunos dos falsos amigos do conceito. Desse modo, devemos fazer do ensino de filosofia um ensino da diferença e criar linhas de fuga à um ensino da forma, da normalidade e da repetição, como é apresentado pelos PCNs e PCNEMs. 


\section{Referências}

ASPIS, Renata Lima e GALLO, Silvio. Ensinar Filosofia: um livro para professores. São Paulo: Ed. Atta Mídia e Educação, 2009.

BIANCO, Giuseppe. Otimismo, Pessimismo, Criação ${ }^{I}$ : Pedagogia do conceito e resistência. Campinas, Euc. Soc., vol. 26, Set/Dez. 2005. p. 1298-1308. Disponível em <http://www.scielo.br/pdf/es/v26n93/27280.pdf>. Acesso em: 29 out. 2019.

BIANCO, Giuseppe. Gilles Deleuze Educador: sobre a pedagogia do conceito. Tradução: Tomaz Tadeu. Educação \& Realidade, Porto Alegre, vol. 27, nº 2. Faculdade de Educação/UFRGS, jul/dez. $2002 . \quad$ p. $2179-204 . \quad$ Disponivel em $<$ https://seer.ufrgs.br/educacaoerealidade/article/view/25927>. Acesso em : 29 out. 2019.

BRASIL. Lei, 9.394 de 20 de Dezembro de 1996. Brasília: Câmera dos Deputados, 1996. Disponível em < http://www.planalto.gov.br/ccivil_03/leis/L9394.htm>. Acesso em: 29out. 2019.

COSSUTA, Frédéric. Elementos para leitura dos textos filosóficos. São Paulo: Martins Fontes, 1994.

DELEUZE, Gilles. Cinema II:A Imagem-Tempo. Tradução: Eloísa de Araújo Ribeiro. Revisão Filosófica: Renato Janine Ribeiro. São Paulo: Ed. Brasiliense, 2007.

DELEUZE, Gilles. Lógica do sentido. Tradução: Luiz Roberto Salinas Forte. São Paulo: Ed. Perspectiva, 2011.

DELEUZE, Gilles e PARNET, Claire. Diálogos. Tradução Eloisa Araújo Ribeiro. São Paulo: Ed. Escuta, 1998.

DELEUZE, Gilles. Abecédario. - com Claire Parnet Versão brasileira, legendado pelo MEC: Tv Escola, 2001.

DELEUZE, Gilles e GUATTARI, Félix. Mil Platôs: Capitalismo e Esquiziofrenia -vol 3 Tradução: Aurélio Guerra, Ana Lúcia de Oliveira, Lúcia Cláudia Leão e Suely Rolnik.. $2^{\mathrm{a}}$ ed. $4^{\mathrm{a}}$ reimp. São Paulo: Editora 34, 2012a.

DELEUZE, Gilles e GUATTARI, Félix. Mil Platôs: Capitalismo e Esquiziofrenia - vol 5 Tradução: Peter Pál Pelbart e Janice Caiafa. $2^{a}$ ed. São Paulo: Editora 34, 2012b.

DELEUZE, Gilles e GUATTARI, Félix. Kafka: por uma literatura menor. Tradução: Cíntia Vieira da Silva, revisão da tradução: Luiz B. L. Orlandi, $1^{a}$ ed. $3^{a}$ reimp. Belo Horizonte: Ed. Autêntica, 2017.

DELEUZE, Gilles. O que é o ato de criação? Dois regimes de Loucos. Tradução de Guilherme Ivo; edição preparada por David Lapoujade; revisão técnica de Luiz B. L. Orlandi. São Paulo: Editora 34, 2016, p. 332-343.

DELEUZE, Gilles. Proust e os signos. Tradução: Antônio Piquet e Roberto Machado. $2^{\text {a }}$ ed. Rio de Janeiro, Ed. Forence Universitária, 2006a.

DELEUZE, Gilles. Diferença e repetição. Tradução: Luiz Orlandi e Roberto Machado. $2^{a}$ ed. Rio de Janeiro, Ed. Graal, 2006b.

DELEUZE, Gilles e GUATTARI, Félix. O que é a filosofia?. Tradução: Bento prado Jr. E Alberto Alonso Muñoz. $2^{a}$ ed. $1^{\text {a }}$ remp. São Paulo: Ed. Editora 34, 1997a.

DELEUZE, Gilles e GUATTARI, Félix. Mil Platôs: Capitalismo e Esquiziofrenia - vol 4 Tradução: Suely Rolnik. São Paulo: Editora 34, 1997b.

DELEUZE, Gilles. Conversações, 1972-1990. Tradução: Peter Pál Pelbart. $1^{\text {a }}$ ed. $7^{\text {a }}$ remp. Rio de Janeiro, Ed. 34, 1992.

DIAS, Sousa. Lógica do Acontecimento: Deleuze e a Filosofia. Porto: Ed. Edições Afrontamento, 1995.

JARDIM, Alex Fabiano Correia; OLIVEIRA, Adhemar Santos de. O ensino de filosofia no processo de resistência. Griot : Revista de Filosofia, Amargosa-BA, v.20, n.2, p.332-346, junho, 2020. 
GALLO, Silvio. Deleuze e a Educação. $3^{\mathrm{a}}$ ed.; $1^{\mathrm{a}}$ remp. Belo Horizonte: Ed. Autêntica, 2016a.

GALLO, Silvio. Em torno de uma educação menor: variáveis e variações. Filosofia da diferença e educação. Maria dos Remédios de Brito e Sílvio Gallo (orgs.). São Paulo: Ed. Livraria da Física, 2016b. p. 15-46.

GALLO, Silvio.. Metodologia do ensino de filosofia: Uma didática para o ensino médio. São Paulo: Ed. Papirus, 2012.

LA SALVIA, André Luis. Problemas de uma pedagogia do conceito: pensando um ensino de filosofia. Rio de Janeiro: Ed. Livros Ilimitados, 2016.

NIETZSCHE, Friederich. Escritos sobre a educação. Tradução: Noéli Correia de Melo Sobrinho. Rio de Janeiro: Ed. PUC-RIO; São Paulo: Ed. Loyola, 2003.

NIETZSCHE, Friederich. Ecce Homo: Como alguém se torna o que é. Tradução: Paulo César de Souza. São Paulo: Ed. Companhia das Letras, 1995.

ZOURABICHVILI, François. Deleuze: uma filosofia do acontecimento. Tradução Luiz B. L. Orlandi. São Paulo: Editora 34, 2016.

ZOURABICHVILI, François. O vocabulário de Deleuze. Tradução André Telles. Rio de Janeiro: Ed. Ediouro, 2004.

Contribuição dos(as) autores(as): Alex Fabiano Correia Jardim e Adhemar Santos de Oliveira participaram da pesquisa, discussão e redação do artigo. Ambos aceitaram e aprovaram a versão final do texto.

Autor(a) para correspondência: Alex Fabiano Correia Jardim, Universidade Estadual de Montes Claros, campus universitario prof. Darcy Ribeiro, 39401-089, Montes Claros - MG Brasil. alex.jardim38@hotmail.com

JARDIM, Alex Fabiano Correia; OLIVEIRA, Adhemar Santos de. O ensino de filosofia no processo de resistência. Griot : Revista de Filosofia, Amargosa - BA, v.20, n.2, p.332-346, junho, 2020. 